\title{
Effect of Finishing and Coiling Temperatures on the Nanoprecipitate Dispersion in Novel HSLA Steels
}

\author{
S Deligiannis $^{1 *}$, A Alexandratou ${ }^{1}$, NI Makris ${ }^{1}, \mathrm{P}_{\text {Tsakiridis }}{ }^{1}$ and G Fourlaris ${ }^{1}$ \\ 1. Lab. of Physical Metallurgy and Center for Electron Microscopy, School of Mining and Metallurgical \\ Engineering, National Technical University of Athens, H. Polytechniou 9, Athens, Greece. \\ *Corresponding author: stavrosde1123@gmail.com
}

High Strength Low Alloy (HSLA) strip steel products are of great importance to the automotive industry, since they are designed to provide an excellent combination of strength, formability and toughness. Automotive and steel making producers have carried out research for developing novel high strength strip steels, focusing on altering alloying compositions as well as the thermomechanical controlled processing in order to obtain the most desirable mechanical properties [1].

Thermomechanical controlled processing (TMCP) of HSLA strip steels, suitably conditions the steel microstructure, resulting in a predominantly ferritic microstructure with formation of second phase nanoprecipitates [2]. The influence of these fine precipitates on the overall mechanical properties of a steel grade, depends on the size, shape and their spatial distributions occurring when altering the TMCP parameters, such as the finishing temperature (FT), the coiling temperature (CT) or the cooling rates from FT to CT. Titanium, vanadium and niobium are the most significant micro-alloying elements acting as carbide and nitride formers, promoting grain refinement and dislocation mobility retardation [2]. In this study, the materials investigated are two novel experimental model HSLA grades, with controlled overall alloy compositions, based on titanium only and combined titanium-vanadium additions.

Previous work has confirmed the role of CT on the strengthening for both steel grades and especially on the Ti-V steel. Moreover, following microstructural investigation, fine precipitation of titanium carbides and a second precipitation sequence of interphase titanium-vanadium carbides for the Ti-V grade, was observed [3]. TMCP was carried out using a Gleeble 3500 thermomechanical simulation system and the treatment applied is depicted in Fig.1. Finishing and coiling temperatures (FT and CT) were considered as variables, in order to investigate their contribution to the mechanical properties of both steel grades as well as their effect on the dispersion of second phase carbide nanoprecipitates. For that reason, two finishing temperatures and three coiling temperatures were employed: $\mathrm{FT}=800^{\circ} \mathrm{C}$ and $850^{\circ} \mathrm{C}$ and $\mathrm{CT}=$ $550^{\circ} \mathrm{C}, 650^{\circ} \mathrm{C}$ and $750^{\circ} \mathrm{C}$.

The results from the present study highlight that FT, but also CT, play a significant role on the strengthening sequence of both steel grades. Vickers hardness evolution underlines the fact that Ti-V samples coiled at $650^{\circ} \mathrm{C}$ present a profound hardening effect, regardless the selected FT (Fig. 2). TEM investigation confirmed the effect of FT and CT on the microstructures, where, different distributions of very fine titanium-vanadium carbides for the Ti-V samples were evident (Fig. 3,4). Moreover, slightly coarser vanadium carbides, randomly dispersed within the ferritic matrix were observed (Fig. 5,6).

\section{References:}

[1] D-B Park et al., Mater. Sci. Eng. A 560 (2013), p. 528.

[2] I Tamura et al. in "Thermomechanical Processing of High-strength Low-alloy Steels", (Butterworth 
\& Co. Ltd) p. 155.

[3] S Deligiannis et al., Proceedings of Microscopy \& Microanalysis 24 (S1) (2018), p. 2230.

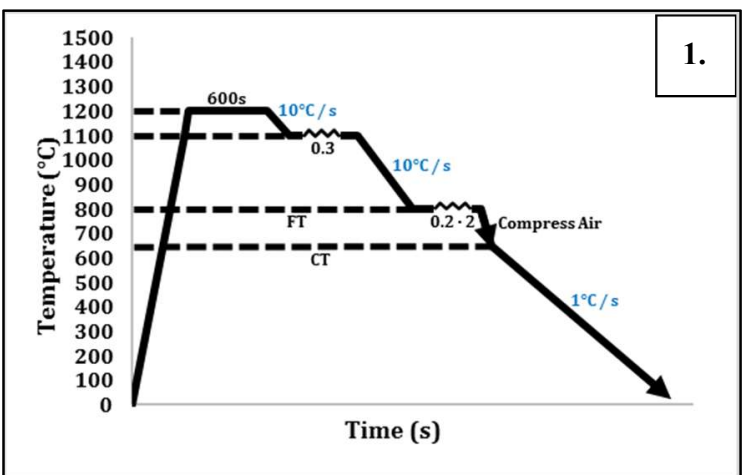

Figure 1. TCMP sequences applied.

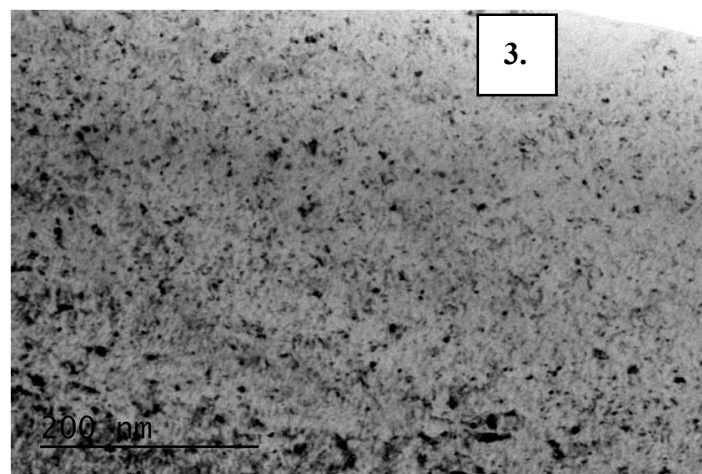

Figure 3. BF TEM micrograph of Ti-V Figure 4. BF TEM micrograph of Ti-V sample $\quad\left(\mathrm{FT}=800^{\circ} \mathrm{C}, \quad \mathrm{CT}=650^{\circ} \mathrm{C}\right)$, sample $\quad\left(\mathrm{FT}=800^{\circ} \mathrm{C}, \quad \mathrm{CT}=550^{\circ} \mathrm{C}\right)$, showing the random distribution of (Ti- showing well defined distributions of $\mathrm{V}) \mathrm{C}$ precipitates $(\approx 5-10 \mathrm{~nm})$ within the interphase $(\mathrm{Ti}-\mathrm{V}) \mathrm{C}$ precipitates $(\approx 5-10$ ferritic matrix.

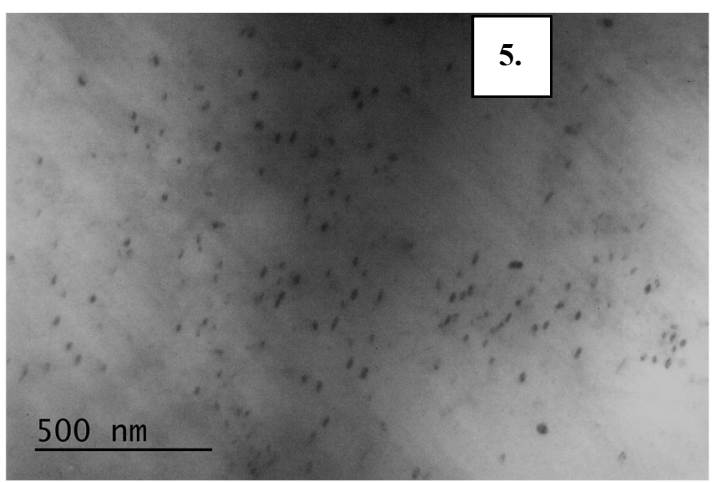

Figure 5. BF TEM micrograph of $\mathrm{Ti}-\mathrm{V}$ sample $\quad\left(\mathrm{FT}=800^{\circ} \mathrm{C}, \quad \mathrm{CT}=650^{\circ} \mathrm{C}\right)$, showing very dense distribution of $\mathrm{VC}$ precipitates $\quad(\approx 20 \mathrm{~nm}), \quad$ randomly dispersed within the ferritic matrix.

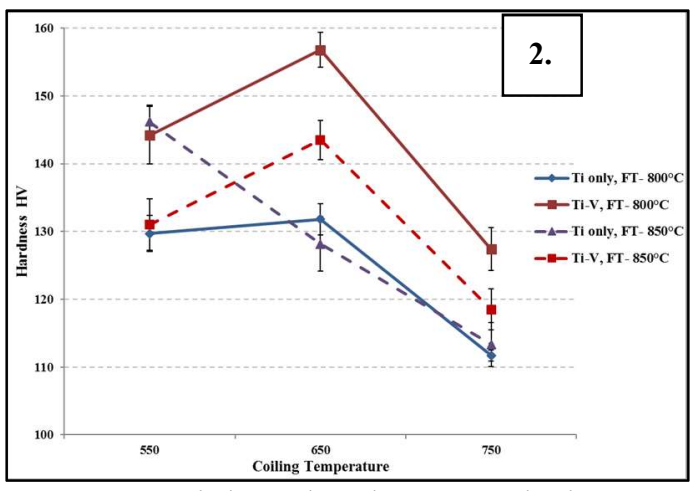

Figure 2. Vickers hardness evolution.

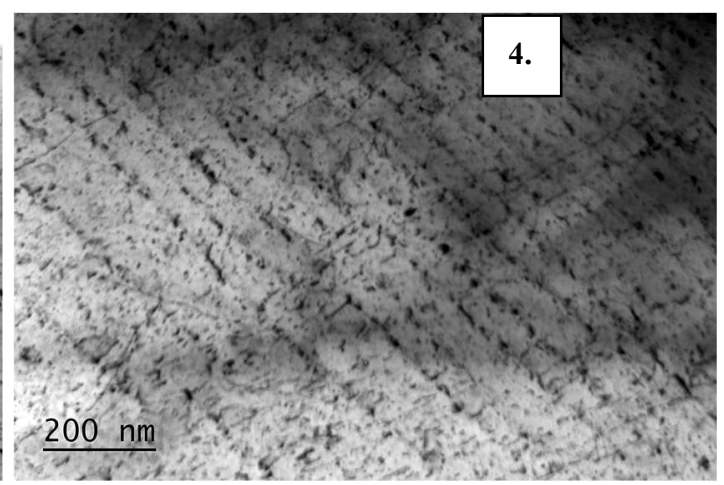

$\mathrm{nm}$ ) within the ferritic matrix.

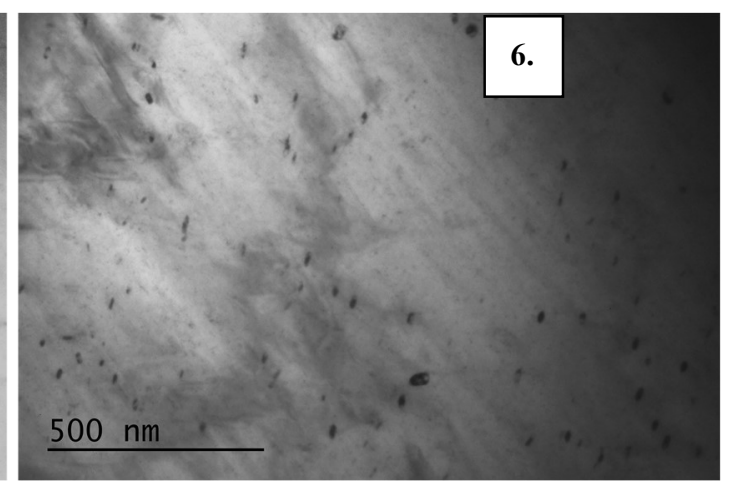

Figure 6. BF TEM micrograph of Ti-V sample $\quad\left(\mathrm{FT}=850^{\circ} \mathrm{C}, \quad \mathrm{CT}=550^{\circ} \mathrm{C}\right)$, showing slightly poorer distribution of VC precipitates $(\approx 20 \mathrm{~nm})$, randomly dispersed within the ferritic matrix. 